\title{
The Response to Nitric Oxide of the Nitrogen-Fixing Symbiont Sinorhizobium meliloti
}

\author{
Eliane Meilhoc, Yvan Cam, Agnès Skapski, and Claude Bruand \\ Laboratoire des Interactions Plantes Microorganismes (LIPM), UMR441-2594 INRA-CNRS BP52627, F-31320 Castanet- \\ Tolosan, France
}

Submitted 15 November 2009. Accepted 25 January 2010.

\begin{abstract}
Nitric oxide (NO) is crucial in animal- and plant-pathogen interactions, during which it participates in host defense response and resistance. Indications for the presence of NO during the symbiotic interaction between the model legume Medicago truncatula and its symbiont Sinorhizobium meliloti have been reported but the role of NO in symbiosis is far from being elucidated. Our objective was to understand the role or roles played by NO in symbiosis. As a first step toward this goal, we analyzed the bacterial response to NO in culture, using a transcriptomic approach. We identified approximately 100 bacterial genes whose expression is upregulated in the presence of NO. Surprisingly, most of these genes are regulated by the two-component system FixLJ, known to control the majority of rhizobial genes expressed in planta in mature nodules, or the NO-dedicated regulator NnrR. Among the genes responding to NO is $h m p$, encoding a putative flavohemoglobin. We report that an hmp mutant displays a higher sensitivity toward NO in culture and leads to a reduced nitrogen fixation efficiency in planta. Because flavohemoglobins are known to detoxify NO in numerous bacterial species, this result is the first indication of the importance of the bacterial NO response in symbiosis.
\end{abstract}

Nitric oxide (NO) is a water-soluble, free-radical reactive gas known to play a number of different roles in biological systems. NO plays a key role in intracellular signaling but is also potentially toxic due to its reaction with a variety of cellular targets, especially thiols and transition metal centers in proteins. It is also part of the antibacterial arsenal of mammalian cells. Thus, the inducible NO-synthase of macrophages generates toxic amounts of NO from arginine, in an attempt to kill off invading microorganisms. To counteract this hazard, bacteria have evolved a number of defense systems that make them capable of protecting themselves against NO stress. Bacterial responses to NO have been studied in model species Escherichia coli (Justino et al. 2005) and Bacillus subtilis (Moore et al. 2004), human pathogens Mycobacterium tuberculosis (Ohno et al. 2003), Salmonella typhimurium (Bang et al. 2006), and others (Elvers et al. 2004; Richardson et al. 2006), and to a lesser extent, in phytopathogenic bacteria (Boccara et al. 2005; Mur et al. 2006). It has become apparent that multiple regulatory systems mediate the response to NO exposure,

Corresponding author: E. Meilhoc; Telephone: +(33) 561285320; E-mail: Eliane.Meilhoc@toulouse.inra.fr

* The $\boldsymbol{e}$-Xtra logo stands for "electronic extra" and indicates that two supplementary figures and one supplementary table are published online. some of them NO unspecific (SoxR, OxyR, Fur, and Fnr), while others could be dedicated NO sensors (NorR and probably NsrR) (Spiro 2007, 2008).

Different mechanisms are used by bacteria to counteract NO stress. One of the most frequent is the degradation of NO by a flavohemoglobin with nitrate as end product (Gardner et al. 1998; Gardner 2005; Angelo et al. 2008). Flavohemoglobins have been shown to protect against NO both anaerobically and aerobically (Justino et al. 2005), although NO consumption is more efficient in the presence of oxygen. Flavohemoglobins are important for the virulence of many bacteria such as E. coli (Stevanin et al. 2007), Staphylococcus aureus (Richardson et al. 2006), and S. typhimurium (Bang et al. 2006). Flavohemoglobin-like proteins have also been identified in numerous plant pathogens and, although little is known about their roles in these bacteria, it has been shown, in Erwinia chrysanthemi, that $h m p X$ is a NO-related pathogenicity determinant (Favey et al. 1995). HmpX consumes NO and prevents inhibition by NO of cell respiration, indicating a role in protection from nitrosative stress. It was shown more recently that $h m p X$ affects the plant hypersensitive response by intercepting NO produced by the host (Boccara et al. 2005). Other systems of NO detoxification can play a role in NO response and be determinants of virulence. Neisseria meningitidis norB (Stevanin et al. 2005) and Brucella suis norD (Loisel-Meyer et al. 2006) are both involved in NO degradation. $N$. meningitidis cycP encodes cytochrome $c^{\prime}$, a single heme-containing molecule, which binds and detoxifies NO in Rhodobacter capsulatus (Cross et al. 2000).

NO may also play a role in symbiotic interactions. During colonization of the squid light organ by Vibrio fischeri, NO is synthesized by the host tissues and may help to exclude nonsymbiotic bacterial species (Davidson et al. 2004). The interaction between legume plants and some soil bacteria, collectively called rhizobia, leads to the establishment of symbiotic relationships, characterized by the formation of new differentiated root organs called nodules which provide a niche for bacterial nitrogen fixation. Several indications of the occurrence of NO during legume-rhizobia interactions have been reported. For example, NO bound to $\mathrm{Lb}$ as nitrosylleghaemoglobin (LbNO) was detected in nodules of soybean infected by Bradyrhizobium japonicum (Mathieu et al. 1998; Meakin et al. 2007), and NO was transiently observed in Lotus japonicus and Medicago sativa roots $4 \mathrm{~h}$ after infection by their cognate symbiont (Mesorhizobium loti and Sinorhizobium meliloti, respectively) (Nagata et al. 2008; Shimoda et al. 2005). Interestingly, class-1 hemoglobin $\mathrm{Hb} 1$ is able to complex with $\mathrm{NO}$ and is present on the site of NO production, suggesting that modulation of NO levels and expression of $\mathrm{Hb} 1$ are involved in the establishment of the symbiosis (Nagata et al. 2008). Overexpression of $\mathrm{Hb} 1$ 
enhances symbiotic nitrogen fixation activity, probably by removing NO as an inhibitor of nitrogenase (Shimoda et al. 2009). Moreover, Baudouin and colleagues clearly showed the presence of NO in functional nodules of Medicago truncatula infected by $S$. meliloti (Baudouin et al. 2006). NO was localized in infected cells of the nodule fixation zone. Pii and coworkers (2007) confirmed this observation and extended it to $M$. sativa. However, the role, if any, of this molecule in the symbiotic interaction remains unknown.

In contrast to all that has been carried out in other bacterial species, the response of rhizobia to the presence of NO has been poorly documented. In $B$. japonicum, only a few genes are known to be induced by the presence of NO. These genes are involved in the denitrification process, which is the complete reduction of nitrate or nitrite to $\mathrm{N}_{2}$ with $\mathrm{NO}$ as intermediate (Bedmar et al. 2005). These genes were shown to be controlled by NnrR, whose expression is under the control of the FixLJ-FixK $_{2}$ signaling pathway (Mesa et al. 2003). The role in symbiosis of one of these genes, encoding the NO reductase, has been studied by analyzing the ability of a norC mutant to consume NO. The norC nodule bacteria were proficient in the ability to consume $\mathrm{NO}$ and the mutation had no effect on NO level, suggesting that other systems may be involved in NO detoxification (Meakin et al. 2006). The NO response of $S$. meliloti has been even less characterized than that of $B$. japonicum. A conserved operon has been shown to be induced by the presence of NO (de Bruijn et al. 2006). This operon encodes putative proteases, a possible sterol-binding protein, and a protein of unknown function. However, mutants in this operon displayed a wild-type phenotype in planta, indicating that these genes do not have an essential role in symbiosis.

How rhizobia cope with the presence of $\mathrm{NO}$ in nodules and what role is played by the bacterial NO response in the interaction with the host plant are questions far from being solved. As a first step to answer these questions, we report in this study on the identification of $S$. meliloti genes upregulated in the presence of $\mathrm{NO}$ and on regulators involved in the transcriptional activation of these genes. One of the genes ( $\mathrm{hmp}$ ) belonging to the NO stimulon encodes a flavohemoglobin, and hmp mutants displayed a deficiency in nitrogen fixation, suggesting that flavohemoglobin and NO have a role during the interaction between $S$. meliloti and alfalfa or the model plant M. truncatula.

\section{RESULTS}

\section{Optimal conditions for transcriptomic studies}

\section{in the presence of $\mathrm{NO}$.}

The global assessment of genes induced by NO was performed by means of a transcriptomic approach. Preliminary experiments were completed to determine the optimal NO concentration and length of exposure at which the subsequent experiments would be carried out. Spermine NONOate (SpNN) was used as a NO donor. Various concentrations of SpNN ranging from 0 to $500 \mu \mathrm{M}$ were tested for cell growth. The results are presented in Figure 1A. For the lowest concentration tested $(10 \mu \mathrm{M})$, no visible effect on growth of the wild-type strain (Rm1021) was observed whereas a modest slow down was detected at $25 \mu \mathrm{M}$. At concentrations of $50 \mu \mathrm{M}$ and above, a transient growth arrest was observed whose length increased with the concentration of NO donor in the medium.

Two genes (sma1289 and sma1294) were already known to be induced by NO (de Bruijn et al. 2006). In order to monitor their expression, we constructed genomic $\beta$-glucuronidase (gus) transcriptional fusions to each of these genes by insertion of a suicide plasmid (discussed below). The gus activity was measured at the highest NO donor concentration $(25 \mu \mathrm{M})$ which did not display a transient growth arrest. Both fusions were induced, with an optimum reached when cells were exposed to NO for $1.5 \mathrm{~h}$ (Fig. 1B).

Hence, on the basis of these indications, a first set of preliminary microarrays was set up where the transcriptome of the wild-type strain in the presence of NO donor $(25 \mu \mathrm{M}$ for 0.5 or $1.5 \mathrm{~h})$ was compared with that of the same strain without NO donor. Genes were considered as induced when a threefold increase of gene expression was obtained in the presence of NO donor compared with the control condition. Using this criterion, similar numbers of genes were induced in the presence of $25 \mu \mathrm{M}$ $\mathrm{SpNN}$ for $30 \mathrm{~min}$ or for $1.5 \mathrm{~h}$. Among the genes induced after $1.5 \mathrm{~h}$ of incubation, we found the sigma factor-encoding gene rpoE2 as well as many genes whose expression is dependent
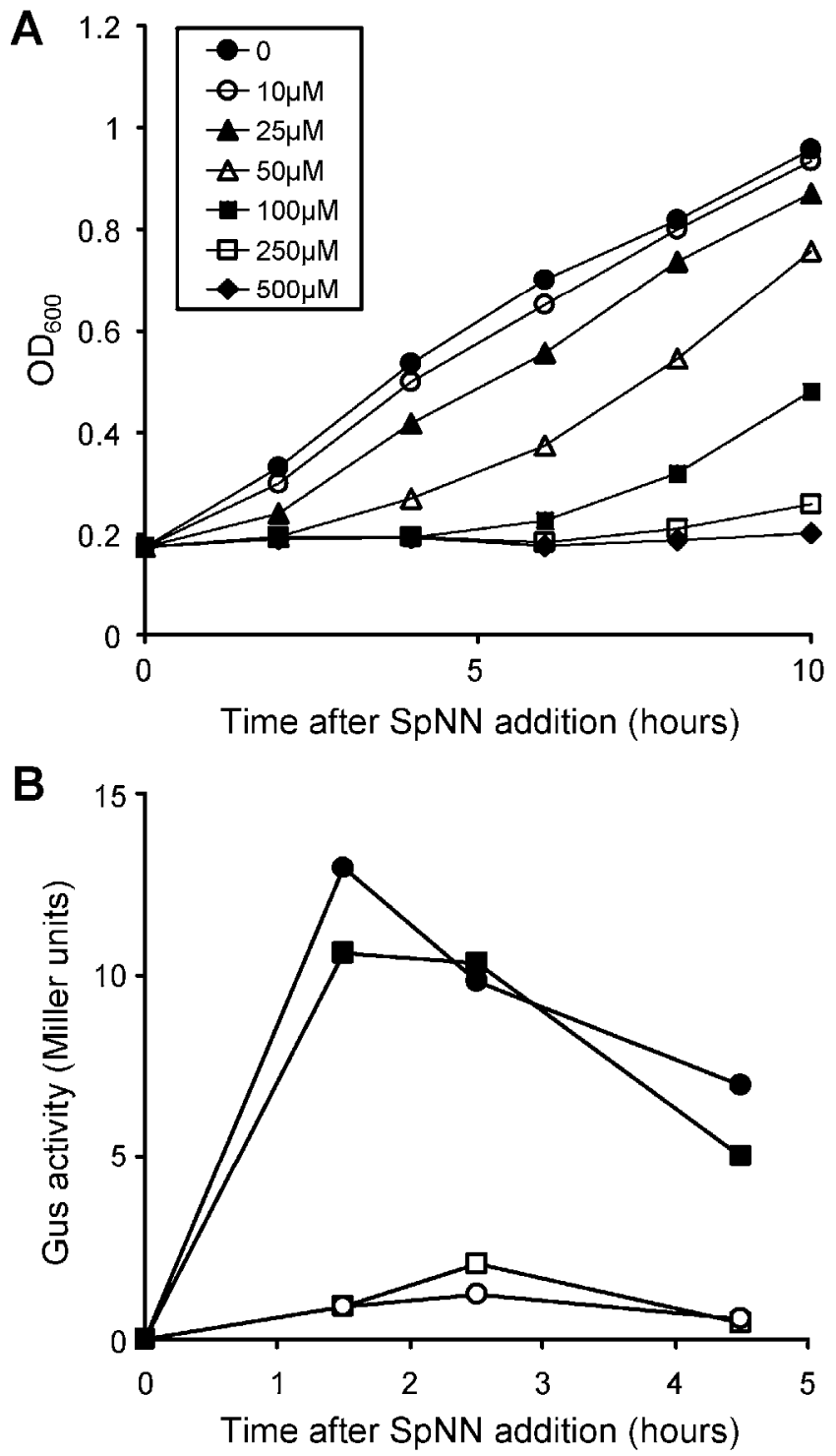

Fig. 1. Spermine NONOate $(\mathrm{SpNN})(25 \mu \mathrm{M})$ has a limited effect on cell growth and is sufficient to induce a transcriptional nitric oxide (NO) response. A, Sinorhizobium meliloti Rm1021 cells were cultured exponentially without or with various concentrations of $\mathrm{SpNN}$ as indicated. Cell growth was measured (optical density at $600 \mathrm{~nm}\left[\mathrm{OD}_{600}\right]$ ) every $2 \mathrm{~h}$ after addition of the compound. B, S. meliloti strains CBT731 or CBT732, carrying a genomic $\beta$-glucuronidase (gus) fusion to either sma1289 (squares) or sma1294 (circles), respectively, were cultured exponentially without (open symbols) or with (black symbols) SpNN $(25 \mu \mathrm{M})$. At different times after addition of the molecule, aliquots of the cultures were collected and tested for gus activity. The figure shows the results of a typical experiment (for each time point, $n=1$ ) that was reproduced three times with similar results. 
upon this factor (data not shown). RpoE2 was recently described as a sigma factor involved in the general stress response of $S$. meliloti (Sauviac et al. 2007) and its apparent activation could reflect a stress response rather than a specific NO response. In contrast, rpoE2 was not induced after 30 min of incubation with $\mathrm{SpNN}$. This was confirmed by real-time quantitative reversetranscription polymerase chain reaction (qRT-PCR) (data not shown). Therefore, incubation for $30 \mathrm{~min}$ in the presence of 25 $\mu \mathrm{M}$ SpNN was chosen for further experiments.

\section{NO upregulates approximately 100 genes}

in $S$. meliloti free-living cells.

We compared the transcript levels in the wild-type strain grown without or with $25 \mu \mathrm{M}$ SpNN for $30 \mathrm{~min}$. We consid-

Table 1. Nitric oxide (NO) upregulated genes as identified with microarrays ${ }^{\mathrm{a}}$

\begin{tabular}{|c|c|c|c|c|c|c|}
\hline \multirow[b]{2}{*}{ Gene ID $^{\mathbf{b}}$} & \multirow[b]{2}{*}{ Gene description } & \multicolumn{2}{|c|}{ Wild type (wt) } & \multicolumn{2}{|c|}{ fix.J } & \multirow{2}{*}{$\begin{array}{c}\text { Ratio } \\
\text { wt/fixJ }\end{array}$} \\
\hline & & FC & $\boldsymbol{P}$ & FC & $P$ & \\
\hline \multicolumn{7}{|c|}{ FixJ-dependent } \\
\hline SMa0633 & Hypothetical protein & 4.1 & 0.01 & 1.2 & 0.58 & 3.3 \\
\hline $\mathrm{SMa0657}$ & Cytochrome $\mathrm{c}$ binding protein; probable amino term & 3.2 & 0.01 & 1.6 & 0.15 & 2.0 \\
\hline SMa0669 & Hypothetical transmembrane protein; HlyD-family & 5.6 & 0.01 & 1.1 & & 5.0 \\
\hline SMa0762 & FixK2 transcription regulator & 23.0 & 0.01 & 2.0 & 0.52 & 11.5 \\
\hline SMa0763 & Hypothetical protein & 10.0 & 0.04 & 2.4 & 0.14 & 4.3 \\
\hline SMa0767 & FixQ2 cbb3-type cytochrome oxidase & 6.9 & 0.04 & 1.2 & 0.60 & 5.8 \\
\hline SMa0815 & NifA transcriptional activator & 3.9 & 0.03 & 1.5 & 0.23 & 2.5 \\
\hline SMa1082 & Hypothetical protein & 11.0 & 0.01 & 2.8 & 0.01 & 4.1 \\
\hline SMa1084 & Probable phosphoketolase & 4.5 & 0.01 & 2.2 & 0.11 & 2.1 \\
\hline SMa1091 & Hypothetical protein & 4.1 & $<0.01$ & 1.8 & 0.01 & 2.3 \\
\hline SMa1093 & Hypothetical protein & 3.7 & 0.02 & 1.6 & 0.06 & 2.3 \\
\hline SMa1095 & Conserved hypothetical protein & 3.3 & 0.02 & 1.3 & 0.41 & 2.5 \\
\hline SMa1101 & Hypothetical protein & 4.4 & 0.02 & 2.2 & 0.01 & 2.0 \\
\hline SMa1103 & Adenylate/guanylate cyclase & 5.1 & 0.01 & 2.2 & 0.01 & 2.3 \\
\hline SMa1120 & ABC transporter; ATP binding protein. hypothetical & 6.4 & $<0.01$ & 2.7 & $<0.01$ & 2.4 \\
\hline SMa1126 & Putative protease; transmembrane protein & 6.7 & 0.01 & 1.9 & 0.08 & 3.5 \\
\hline SMa1128 & DegP4 protease like protein & 4.5 & 0.01 & 1.5 & 0.19 & 3.0 \\
\hline SMa1131 & Metallo- $\beta$-lactamase superfamily protein & 3.6 & $<0.01$ & 1.7 & 0.07 & 2.1 \\
\hline SMa1138 & Truncated response regulator & 3.4 & 0.01 & 1.5 & 0.05 & 2.3 \\
\hline SMa1146 & Conserved hypothetical protein & 5.7 & 0.01 & 2.7 & $<0.01$ & 2.1 \\
\hline SMa1147 & Conserved hypothetical protein & 25.0 & $<0.01$ & 4.6 & $<0.01$ & 5.4 \\
\hline SMa1149 & Conserved hypothetical protein & 9.3 & 0.02 & 2.0 & 0.04 & 4.6 \\
\hline SMa1153 & Hypothetical protein & 5.9 & 0.01 & 1.9 & 0.26 & 3.1 \\
\hline SMa1154 & Hypothetical protein & 18.0 & 0.01 & 2.2 & $<0.01$ & 8.1 \\
\hline SMa1155 & Cation transport P-type ATPase. hypothetical & 3.9 & 0.04 & 1.4 & 0.17 & 2.7 \\
\hline SMa1156 & Alcohol dehydrogenase. Zn-dependent class III & 8.2 & 0.03 & 2.5 & 0.06 & 3.3 \\
\hline SMa1158 & Conserved hypothetical protein & 8.9 & 0.04 & 2.5 & 0.01 & 3.6 \\
\hline SMa1170 & Putative CycB2 cytochrome c552 & 10.0 & $<0.01$ & 4.5 & 0.04 & 2.3 \\
\hline SMa1176 & Hypothetical protein & 3.8 & $<0.01$ & 1.6 & 0.10 & 2.4 \\
\hline SMa1184 & NosF copper ABC transporter & 3.8 & $<0.01$ & 1.2 & 0.39 & 3.1 \\
\hline SMa1185 & NosY nitrous oxide metabolic protein & 5.5 & 0.01 & 2.2 & 0.17 & 2.5 \\
\hline SMa1191 & hmp-putative flavohemoglobin like protein & 3.9 & 0.05 & 1.8 & 0.29 & 2.3 \\
\hline SMa1194 & nnrS-Putative haem and copper membrane protein & 4.4 & 0.01 & 2.1 & 0.10 & 2.1 \\
\hline SMa1201 & Hypothetical protein & 8.5 & $<0.01$ & 3.8 & 0.01 & 2.2 \\
\hline SMa1209 & FixI1 copper transport ATPase & 4.9 & $<0.01$ & 1.9 & 0.04 & 2.7 \\
\hline SMa1211 & FixG Iron sulfur membrane protein & 11.0 & 0.01 & 1.8 & 0.17 & 6.2 \\
\hline SMa1213 & FixP1 Di-heme cytochrome c & 5.6 & 0.02 & 1.2 & 0.38 & 4.6 \\
\hline SMa1214 & FixQ1 cbb3-type cytochrome oxidase & 7.0 & 0.04 & 1.5 & 0.03 & 4.5 \\
\hline SMa1220 & FixN1 Heme b/copper cyt-c oxidase subunit & 9.5 & 0.02 & 3.2 & 0.09 & 3.0 \\
\hline SMa1223 & FixM flavoprotein oxidoreductase & 12.0 & 0.03 & 1.2 & 0.90 & 10.2 \\
\hline SMa1225 & FixK1 transcriptional activator & 22.0 & 0.01 & 1.7 & 0.10 & 12.9 \\
\hline SMa1226 & FixT1 inhibitor of FixL autophosphorylation & 5.2 & $<0.01$ & 1.1 & 0.61 & 4.6 \\
\hline SMa1231 & Conserved hypothetical protein & 3.9 & 0.04 & 1.4 & 0.59 & 2.8 \\
\hline SMa1276* & NorC nitric oxide reductase & 14.0 & $<0.01$ & 6.1 & $<0.01$ & 2.3 \\
\hline SMa1283 & NnrU-like transmembrane protein & 16.0 & $<0.01$ & 7.2 & 0.02 & 2.2 \\
\hline SMa1292 & Peptidase & 7.7 & $<0.01$ & 3.8 & $<0.01$ & 2.0 \\
\hline SMa1294* & Hypothetical protein & 4.8 & 0.01 & 2.3 & 0.14 & 2.1 \\
\hline SMa1296 & adhA1-Alcohol dehydrogenase; Zn-dep-class III & 14.0 & $<0.01$ & 6.4 & 0.01 & 2.2 \\
\hline SMb20139 & Conserved hypothetical transmembrane protein & 15.0 & 0.02 & 1.3 & 0.40 & 11.0 \\
\hline $\mathrm{SMb} 20186$ & gfa-Glutathione-dep formaldehyde-activating enz & 6.7 & 0.04 & 1.8 & 0.36 & 3.8 \\
\hline SMb20433 & eutC-Probable ornithine cyclodeaminase & 4.3 & $<0.01$ & 2.1 & 0.01 & 2.1 \\
\hline SMc03253 & L-proline cis-4-hydroxylase & 34.0 & 0.01 & 1.9 & 0.01 & 18.2 \\
\hline SMc03254 & fixT3_putative antikinase protein & 5.3 & 0.03 & 1.1 & 0.59 & 4.6 \\
\hline \multicolumn{7}{|c|}{ FixJ-independent } \\
\hline SMa0625 & Hypothetical protein & 5.2 & 0.01 & 3.8 & 0.01 & 1.4 \\
\hline SMa1086 & Conserved hypothetical protein & 3.2 & 0.01 & 1.7 & 0.19 & 1.9 \\
\hline SMa1087 & Cation transport ATPase & 3.2 & $<0.01$ & 1.8 & 0.05 & 1.8 \\
\hline
\end{tabular}

${ }^{a}$ FC: fold change values of a comparison of Sinorhizobium meliloti cells grown with $(25 \mu \mathrm{M})$ versus without NO donor; $P=P$ value.

${ }^{\mathrm{b}}$ FixJ-dependent and -independent genes in the presence of NO, and Stress = stress-related genes. Gene ID in bold: genes known as FixJ-dependent in microaerobic conditions. Genes with an asterisk $\left(^{*}\right)$ were validated by quantitative reverse-transcription polymerase chain reaction as NnrR dependent. 
ered as differentially expressed genes only those showing an $M$ value $\left(\log _{2}\right.$ ratio of intensities) $>$ or $<1.58$ (fold change of three) and $P$ value $\leq 0.05$ according to $t$ statistics. Approximately 130 genes were downregulated in the presence of SpNN, many of them (approximately 50) encoding ribosomal proteins and translation factors. This indicates an effect of the molecule, even moderate, on cell biosynthetic activity. In this study, only genes induced by NO were considered. Approximately 120 genes were upregulated by NO. In an attempt to eliminate those for which the response might not be specific to $\mathrm{NO}$, we compared them with a list of genes known to respond to different stresses (carbon or nitrogen starvation, heat shock,

Table 1. (continued from preceding page)

\begin{tabular}{|c|c|c|c|c|c|c|}
\hline \multirow[b]{2}{*}{ Gene ID ${ }^{b}$} & \multirow[b]{2}{*}{ Gene description } & \multicolumn{2}{|c|}{ Wild type (wt) } & \multicolumn{2}{|c|}{ fixJ } & \multirow{2}{*}{$\begin{array}{c}\text { Ratio } \\
\text { wt/fixJ }\end{array}$} \\
\hline & & FC & $\boldsymbol{P}$ & FC & $\boldsymbol{P}$ & \\
\hline SMa1132 & Hypothetical protein & 3.9 & 0.02 & 4.2 & 0.06 & 0.9 \\
\hline SMa1134 & Conserved hypothetical protein & 4.8 & $<0.01$ & 2.9 & $<0.01$ & 1.7 \\
\hline SMa1169 & Hypothetical protein & 3.5 & 0.02 & 1.8 & 0.17 & 1.9 \\
\hline SMa1179 & NosR Regulatory protein for $\mathrm{N} 2 \mathrm{O}$ reductase & 3.7 & $<0.01$ & 2.2 & 0.06 & 1.7 \\
\hline SMa1182 & NosZ N2O reductase & 22.0 & $<0.01$ & 11.9 & $<0.01$ & 1.8 \\
\hline SMa1183 & NosD periplasmic copper-binding precursor & 11.0 & $<0.01$ & 6.4 & 0.03 & 1.8 \\
\hline SMa1195* & Conserved hypothetical protein & 7.1 & 0.01 & 3.9 & 0.01 & 1.8 \\
\hline SMa1207 & FixK-like regulatory protein & 16.0 & $<0.01$ & 10.2 & $<0.01$ & 1.6 \\
\hline SMa1233 & NapB periplasmic nitrate reductase & 3.8 & 0.02 & 3.7 & 0.11 & 1.0 \\
\hline SMa1240 & NapF Fd component periplasmic nitrate reductase & 3.6 & 0.02 & 2.3 & 0.12 & 1.5 \\
\hline SMa1243 & Azu1 pseudoazurin (blue copper protein) & 44.0 & $<0.01$ & 42.0 & $<0.01$ & 1.1 \\
\hline SMa1247 & NirV periplasmic nitrate reductase & 4.8 & 0.01 & 2.5 & 0.05 & 1.9 \\
\hline SMa1250* & Putative NirK Cu-nitrite reductase & 3.9 & 0.03 & 2.2 & 0.08 & 1.8 \\
\hline SMa1255 & Conserved hypothetical protein & 3.2 & $<0.01$ & 2.0 & 0.07 & 1.6 \\
\hline SMa1256 & Conserved hypothetical protein & 4.2 & 0.01 & 2.5 & 0.04 & 1.7 \\
\hline SMa1259* & Conserved hypothetical protein & 9.3 & $<0.01$ & 8.1 & $<0.01$ & 1.1 \\
\hline SMa1266 & HemN coproporphyrinogen III oxidase & 16.0 & $<0.01$ & 8.4 & $<0.01$ & 1.9 \\
\hline SMa1273 & NorB nitric oxide reductase & 9.5 & $<0.01$ & 6.9 & $<0.01$ & 1.4 \\
\hline SMa1279 & NorE protein involved in nitric oxide reduction & 3.1 & $<0.01$ & 2.0 & 0.02 & 1.5 \\
\hline SMa1285 & Probable decarboxylase & 4.2 & 0.01 & 3.0 & 0.05 & 1.4 \\
\hline SMa1288* & Carboxy-lyase & 3.1 & $<0.01$ & 1.8 & 0.11 & 1.7 \\
\hline SMa1291 & Conserved hypothetical protein & 16.0 & $<0.01$ & 10.3 & $<0.01$ & 1.5 \\
\hline SMa1521 & Conserved hypothetical protein & 3.0 & 0.02 & 2.8 & 0.01 & 1.1 \\
\hline SMb20663 & Conserved hypothetical protein & 3.1 & $<0.01$ & 2.4 & 0.01 & 1.3 \\
\hline SMb20664 & Putative transcriptional regulator; GntR family protein & 4.2 & $<0.01$ & 3.1 & 0.01 & 1.4 \\
\hline $\mathrm{SMb} 21011$ & xdhA2_probable xanthine dehydrogenase protein & 3.5 & 0.02 & 4.2 & 0.01 & 0.8 \\
\hline SMb21212 & Putative protein & 3.6 & 0.01 & 5.1 & 0.01 & 0.7 \\
\hline $\mathrm{SMb} 21284$ & Putative polysaccharide deacetylase & 3.8 & 0.01 & 3.3 & 0.01 & 1.2 \\
\hline $\mathrm{SMc} 00147$ & Conserved hypothetical protein & 3.0 & 0.01 & 6.4 & 0.01 & 0.5 \\
\hline $\mathrm{SMc} 00167$ & Conserved hypothetical signal peptide protein & 3.1 & 0.02 & 3.7 & 0.01 & 0.8 \\
\hline SMc00276 & Conserved hypothetical protein & 3.6 & 0.01 & 3.7 & 0.04 & 1.0 \\
\hline $\mathrm{SMc} 00277$ & Conserved hypothetical protein & 8.2 & 0.02 & 9.0 & $<0.01$ & 0.9 \\
\hline SMc00316 & Oxidoreductase UbiH/COQ6 family & 4.2 & $<0.01$ & 4.7 & 0.01 & 0.9 \\
\hline SMc00317 & Putative transporter & 4.2 & 0.01 & 3.7 & $<0.01$ & 1.1 \\
\hline SMc00338 & Conserved hypothetical protein & 4.5 & $<0.01$ & 5.2 & 0.01 & 0.9 \\
\hline $\mathrm{SMc} 00470$ & Hypothetical transmembrane protein & 4.4 & 0.02 & 5.0 & 0.01 & 0.9 \\
\hline SMc00507 & Hypothetical protein & 3.9 & 0.05 & 4.1 & 0.02 & 0.9 \\
\hline SMc00998 & Conserved hypothetical signal peptide protein & 3.5 & $<0.01$ & 3.6 & $<0.01$ & 1.0 \\
\hline SMc01022 & Putative cytochrome b transmembrane protein & 4.8 & $<0.01$ & 5.4 & $<0.01$ & 0.9 \\
\hline SMc01843 & metF-Prob. 5.10-methylenetetrahydrofolate reductase & 3.1 & 0.05 & 2.4 & 0.01 & 1.3 \\
\hline SMc02021 & Putative organic acid ABC transporter & 3.0 & 0.05 & 2.8 & 0.01 & 1.1 \\
\hline $\mathrm{SMc} 02239$ & Conserved hypothetical protein & 3.3 & 0.04 & 3.0 & 0.09 & 1.1 \\
\hline SMc02255 & qxtA_putative quinol oxidase subunit & 3.3 & $<0.01$ & 3.3 & 0.01 & 1.0 \\
\hline $\mathrm{SMc} 03834$ & pcbD_putative pterin- $4-\alpha$ carbinolamine dehydratase & 3.7 & 0.02 & 5.8 & 0.01 & 0.6 \\
\hline SMc03835 & ligT_putative $2^{\prime}-5^{\prime}$ RNA ligase protein & 3.6 & 0.01 & 4.5 & 0.01 & 0.8 \\
\hline SMc04150 & Conserved hypothetical protein & 4.0 & 0.02 & 2.5 & $<0.01$ & 1.6 \\
\hline SMc04164 & Hypothetical protein & 3.4 & 0.02 & 5.1 & 0.03 & 0.7 \\
\hline \multicolumn{7}{|l|}{ Stress } \\
\hline $\mathrm{SMa0615}$ & FixO3 cytochrome-c oxidase subunit & 5.5 & 0.01 & 4.5 & 0.01 & 1.2 \\
\hline SMa1104 & Hypothetical protein fragment & 4.5 & $<0.01$ & 3.7 & 0.01 & 1.2 \\
\hline SMa1450 & Thiolase & 3.6 & 0.04 & 4.2 & $<0.01$ & 0.8 \\
\hline SMa1720 & Putative Lysr-R family transcriptional regulator & 3.1 & 0.01 & 3.3 & $<0.01$ & 0.9 \\
\hline $\mathrm{SMb} 20331$ & Hypothetical membrane spanning protein & 3.5 & 0.05 & 3.8 & 0.01 & 0.9 \\
\hline $\mathrm{SMb} 21456$ & Conserved hypothetical protein & 5.4 & $<0.01$ & 6.2 & $<0.01$ & 0.9 \\
\hline SMc00137 & Conserved hypothetical protein & 4.1 & 0.01 & 4.4 & $<0.01$ & 0.9 \\
\hline SMc00506 & Hypothetical transmembrane protein & 4.2 & 0.01 & 4.3 & $<0.01$ & 1.0 \\
\hline SMc00885 & Hypothetical transmembrane signal peptide protein & 3.8 & 0.03 & 1.8 & 0.28 & 2.1 \\
\hline SMc01169 & Ald-probable alanine desydrogenase oxidoreductase & 14.8 & $<0.01$ & 20.1 & $<0.01$ & 0.7 \\
\hline SMc01267 & Conserved hypothetical protein & 4.0 & $<0.01$ & 2.2 & 0.15 & 1.8 \\
\hline SMc01815 & Dihydropyrimidine dehydrogenase family protein & 11.4 & $<0.01$ & 8.4 & $<0.01$ & 1.4 \\
\hline SMc02227 & fadB putative fatty oxidation complex $\alpha$ subunit & 4.0 & 0.01 & 6.6 & $<0.01$ & 0.6 \\
\hline $\mathrm{SMc} 02228$ & fadA putative acetyl CoA acetyltransferase & 7.1 & 0.02 & 8.0 & 0.02 & 0.9 \\
\hline SMc03780 & Conserved hypothetical protein & 3.5 & $<0.01$ & 3.9 & 0.01 & 0.9 \\
\hline SMc03999 & Hypothetical protein & 3.6 & 0.02 & 3.8 & 0.01 & 0.9 \\
\hline
\end{tabular}


or $\mathrm{NaCl}$ ) (Dominguez-Ferreras et al. 2006; Sauviac et al. 2007). Thus, we eliminated 16 genes which were induced under at least two other stress conditions (Table 1). Because SpNN generates NO and spermine in the culture, a control microarray experiment was performed to compare the transcriptomes of cells grown without or with $25 \mu \mathrm{M}$ spermine. No genes were differentially expressed in these conditions, indicating that NO was really responsible for the upregulation of genes mentioned above. Finally, the NO stimulon comprised 103 genes, which are listed in Table 1. Based on predictions of operon structure, approximately 30 genes may have been missed in our analysis; 10 of these were present in our data set but did not meet cutoffs for fold change or $P$ value. Consequently, the NO stimulon could be composed of up to 130 genes. Interestingly, genes already known to be induced by NO (sma1291-sma1294) (de Bruijn et al. 2006) were detected in this study, confirming the validity of the approach used.

\section{FixLJ and NnrR are major regulators of the NO response in $S$. meliloti.}

Strikingly, we observed a remarkable overlap between the microoxia and NO stimulons because $70 \%$ of the genes upregulated in the presence of NO had been previously observed as activated in microaerobic conditions (Bobik et al. 2006). Because the two-component system FixLJ is the major regulator operating in microaerobic conditions in S. meliloti, we suspected that it could be involved in the NO response. Hence, we set up a microarray experiment where we compared the transcriptomes

Table 2. Quantitative reverse-transcription polymerase chain reaction validated NnrR-dependent genes

\begin{tabular}{lcc}
\hline & \multicolumn{2}{c}{ Fold change \pm NO $( \pm \text { SD })^{\mathbf{a}}$} \\
\cline { 2 - 3 } Gene & Wild type & nnrR \\
\hline sma1195 & $399( \pm 165)$ & $56( \pm 34)$ \\
sma1250 $($ nirK $)$ & $914( \pm 384)$ & $73( \pm 39)$ \\
sma1252(nnrS) & $103( \pm 24)$ & $13( \pm 7)$ \\
sma1259 & $856( \pm 456)$ & $205( \pm 230)$ \\
sma1276(norC) & $4,192( \pm 557)$ & $9( \pm 6)$ \\
sma1288 & $102( \pm 50)$ & $7( \pm 6)$ \\
sma1289 & $2,292( \pm 976)$ & $19( \pm 12)$ \\
\hline
\end{tabular}

${ }^{\mathrm{a}} \mathrm{NO}=$ nitric oxide and $\mathrm{SD}=$ standard deviation. of fixJ mutant cells grown in the presence and absence of SpNN $(25 \mu \mathrm{M})$. We considered genes for which the induction level in the presence of NO was reduced at least twofold in the mutant compared with the wild-type strain to be FixJ dependent (Table 1, column 7). Using this criterion, 53 genes were found dependent upon FixJ (Table 1, upper part). Most of them $(n=46)$ were already known to be FixJ targets in microaerobic or symbiotic conditions (Bobik et al. 2006). Direct targets of FixJ (fix $K_{1}, f i x K_{2}$, nifA, and smc03253) were found in this study, and these results were confirmed by qRT-PCR analysis because we measured a gene induction of 700- and 15-fold for fixK and nifA, respectively, in the presence of SpNN compared with the control without NO donor. This activation was dependent upon FixJ because it was abolished in a fixJ mutant in the presence of NO (data not shown). All other FixJ targets had been identified previously as controlled by the intermediate transcriptional regulator FixK and, indeed, most of them display a FixK-binding sequence in their upstream regions (Bobik et al. 2006).

In the response to microoxia, FixJ functions in partnership with its cognate sensor histidine protein kinase FixL. In order to determine whether FixL is also involved in NO sensing, a transcriptomic analysis was performed to compare a fixL to a fixJ mutant in the presence of $\operatorname{SpNN}(25 \mu \mathrm{M})$. No genes were differentially expressed, suggesting that FixL is the kinase responding to NO (data not shown). Therefore, these results show that the two-component system FixLJ is a major regulator of the NO response because it controls, either directly or via FixK, at least half of the NO-induced genes.

Among the 50 genes found to be FixJ independent in the presence of NO (Table 1, lower part), as many as 19 were known to be upregulated under microaerobic conditions in a FixJ-dependent manner (via FixK) (Table 1, lower part, gene ID in bold) (Bobik et al. 2006). Of these 19 genes, 13 could be partly FixJ dependent because the ratio wt/fixJ was found between 1.5 and 2. Among those were genes involved in the denitrification process (nap, nir, nor, and nos). Some of these genes are known to be regulated by the NO-dedicated regulator NnrR in R. sphaeroides (Laratta and Shapleigh 2003) and B. japonicum (Mesa et al. 2003). To test whether these genes are regulated by NnrR in $S$. meliloti, we analyzed the transcriptomes of $n n r R$ mutant cells in the presence or absence of SpNN. In all,

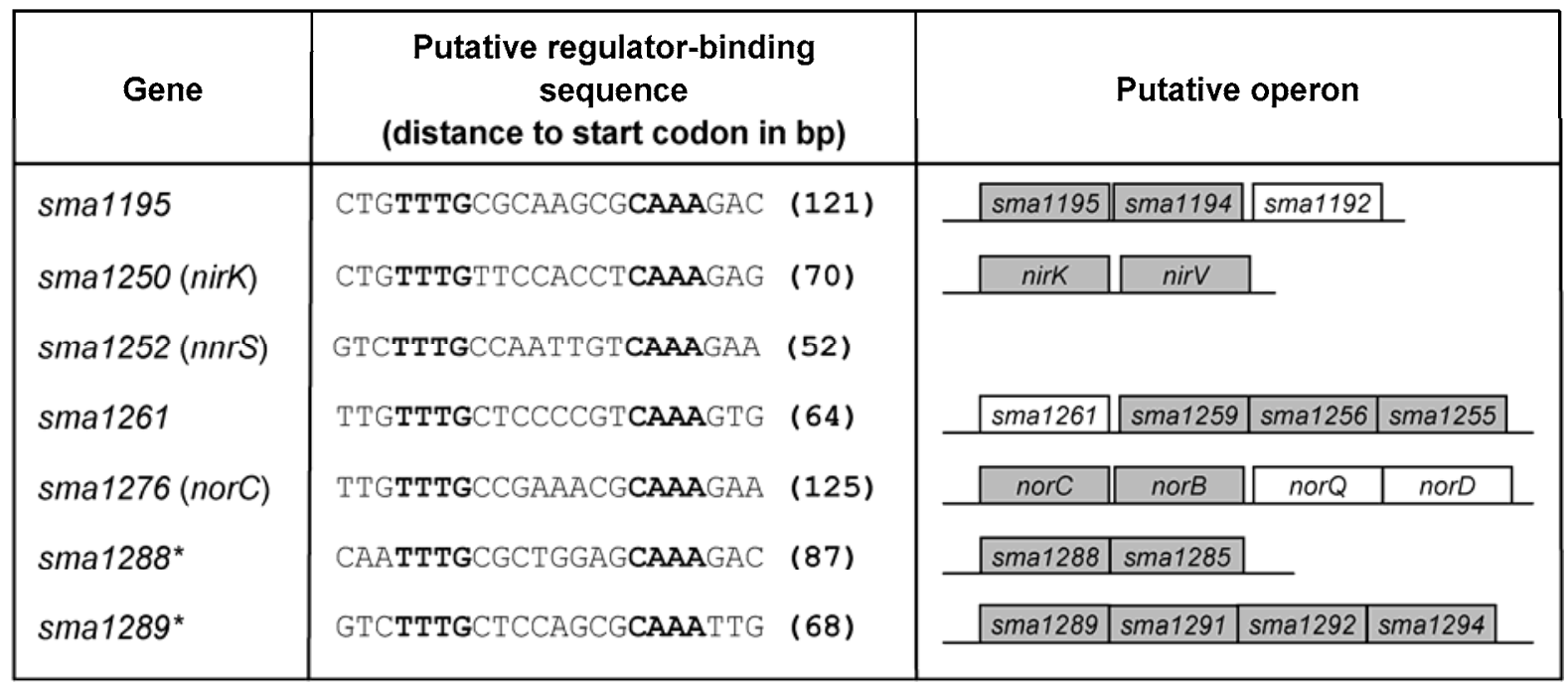

Fig. 2. Putative NnrR-binding sequences in front of NnrR-dependent genes. The first gene of each of the quantitative reverse-transcription polymerase chain reaction-validated NnrR-dependent transcription units is indicated in the first column. Asterisks indicate that the boxes are identical but read in opposite directions. Putative NnrR-binding-sequences are indicated in the second column. The distance to the start codon is indicated from the last nucleotide of the sequence shown in the column. When the transcription unit comprises more than one gene, it is shown in the last column (not to scale), and the genes found to be nitric oxide (NO)-dependent in the present study are indicated in gray. 
22 genes covering 14 transcription units were NnrR dependent (data not shown). However, when assayed by qRT-PCR, only six could be clearly validated (i.e., sma1195, nirK, sma1259, norC, 1288, and sma1289) (Table 2).

Four of these transcription units had been predicted in a previous bioinformatic study (Rodionov et al. 2005), on the basis of the presence of a putative NnrR-binding sequence upstream of these genes (ctTTGcgNNNNcgCAAag). In this analysis, sma1252 (nnrS) also displayed this consensus sequence but was found to be NO induced in our transcriptomic analysis. By using qRT-PCR, we showed that sma1252 was induced (100-fold) in the presence of NO in an NnrRdependent manner (Table 2). Alignment of promoter regions of the seven identified NnrR-dependent transcription units revealed the presence of the sequence TTTGN $_{8}$ CAAA in all of them. Therefore, we conclude that the NnrR regulon contains at least seven transcription units and that the DNA motif TTTGN ${ }_{8}$ CAAA is the likely sequence recognized by NnrR in S. meliloti (Fig. 2).

Among the genes that we failed to validate as FixJ or NnrR dependent, some were shown to be FixLJ/FixK dependent in microaerobic conditions (Table 1, lower part, gene ID in bold) and displayed a FixK-binding recognition sequence TTGAN $_{6}$ T/GCAA in their promoter region (Bobik et al. 2006; Foussard et al. 1997). Interestingly, both FixK and NnrR are regulators of the FNR/CRP family, and their DNAbinding sites display sequence similarities and might overlap (i.e., TTTGAN 6 T/GCAAA). Thus, some $S$. meliloti genes may be regulated by both FixK and NnrR. Although our data show that either FixLJ/FixK or NnrR regulates most genes induced by $\mathrm{NO}$ exposure, it is difficult to assign some of these genes to a specific regulon.

\section{The putative flavohemoglobin encoded by the $h m p$ gene plays a role in the bacterial resistance to NO but also in symbiosis.}

Among the genes upregulated in the presence of NO, one ( hmp) encodes a homologue of the flavohemoglobins characterized in a wide variety of eubacteria (Lira-Ruan et al. 2003) and known for its role in host-microbe interactions (Boccara et al. 2005; Bang et al. 2006; Stevanin et al. 2007). The induction of $h m p$ in cells grown in the presence of NO was verified by qRT-PCR, and by measuring the activity of a genomic hmpgus transcriptional fusion (Supplementary Fig. S1). In addition, expression of $\mathrm{hmp}$ was also detected in nodules.

In order to test whether the $S$. meliloti homologue of Hmp has a biological function in the NO response, we constructed two kinds of mutants and tested their sensitivity to NO in culture. The first mutant ( $\mathrm{hmp}$ ) was a null mutant constructed by integration of a suicide plasmid in the hmp gene. The second mutant $(h m p++)$ overexpressed the flavohemoglobin from plasmid pBBR1-MCS5. qRT-PCR analysis showed that $S$. meliloti cells carrying this plasmid display approximately 1,000 times as much hmp transcripts as the wild-type cells (data not shown). The sensitivity of these mutants to the NO donor SpNN was compared with that of the wild-type strain. As already described above (Fig. 1), addition of SpNN to wild-type (Rm1021) cells led to a transient arrest of cell growth, whose duration was dependent on SpNN concentration (Fig. 3A). We observed that this growth arrest was approximately 90 min longer for the hmp mutant (CBT733) than for the wild strain (Fig. 3A; Supplementary Fig. S2). Similar results were obtained with an hmp::mTn5 mutant strain derived from Rm2011 (GMI11549; data not shown), another $S$. meliloti strain closely related to Rm1021.

The growth of the wild-type strain Rm1021 carrying the empty plasmid pBBR1-MCS5 was completely arrested in cul- ture containing $200 \mu \mathrm{M} \mathrm{SpNN}$ (Fig. 3B). This result was also observed in the wild-type strain without plasmid (Fig. 1). In contrast, the hmp++ strain was resistant to at least $200 \mu \mathrm{M}$ SpNN (Fig. 3B). Comparable results were obtained in the $S$. meliloti Rm2011 background. From all these experiments, we conclude that Hmp plays a role in the resistance to NO, presumably by detoxifying it.

The symbiotic properties of hmp null mutants in either Rm1021 or Rm2011 strain backgrounds were tested on $M$. sativa or M. truncatula, respectively. Both mutants displayed a Nod+ Fix+ phenotype. However, at 38 days postinoculation, the shoot dry weight and nitrogen fixation efficiency were reduced by as much as 30 and $56 \%$, respectively, in M. truncatula infected with the hmp mutant (Rm2011 background) compared with the wild type (Fig. 4). Comparable results were obtained with $S$. meliloti (background Rm1021) and M. sativa, although the percentage of reduction was slightly lower in this case. Therefore, these data showed that Hmp could play a role, to some extent, in symbiosis.
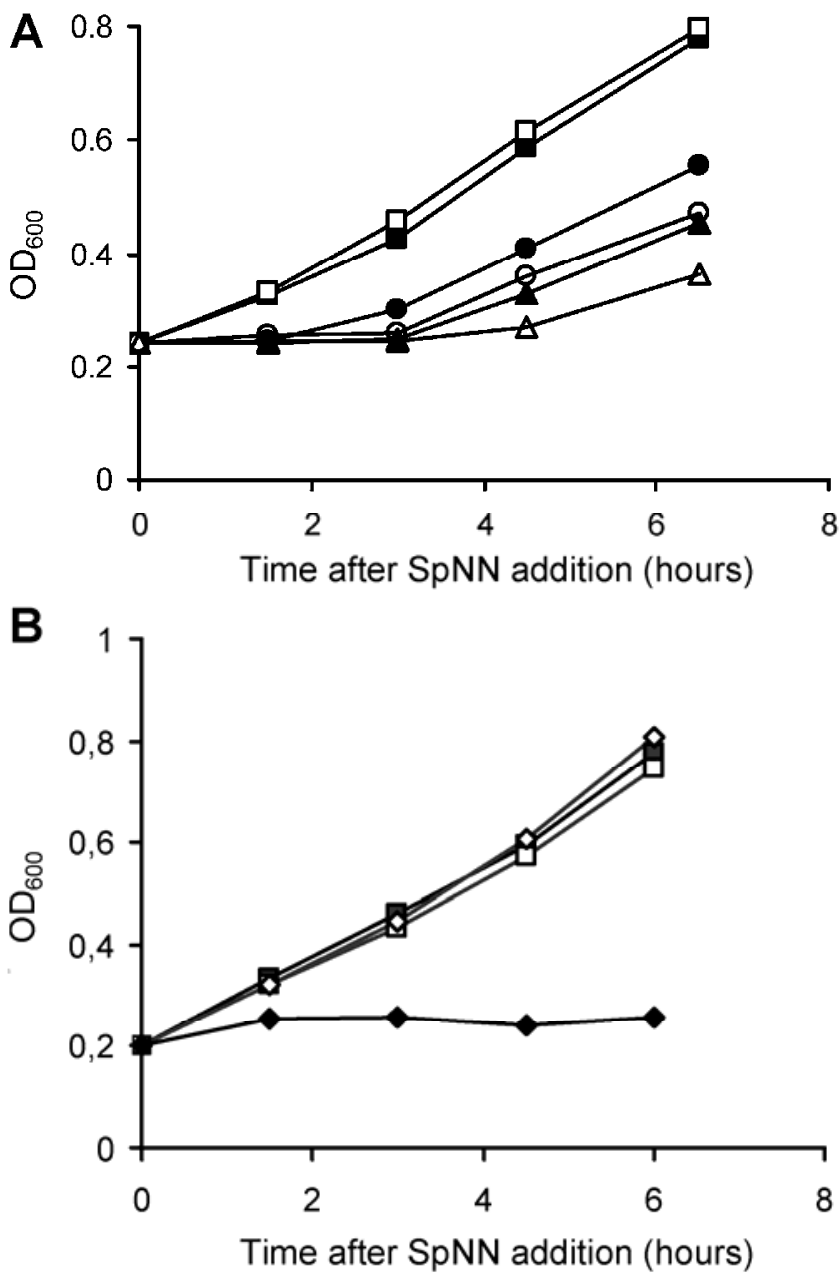

Fig. 3. Hmp is involved in nitric oxide (NO) detoxification in Sinorhizobium meliloti. A, S. meliloti wt cells (black symbols) or hmp mutant cells (CBT733; open symbols) were cultured exponentially in the absence (squares) or presence of $50 \mu \mathrm{M}$ (circles) or $75 \mu \mathrm{M}$ (triangles) Spermine NONOate (SpNN). Cell density (optical density at $600 \mathrm{~nm}\left[\mathrm{OD}_{600}\right]$ ) was monitored over time. The figure shows the results of a typical experiment (for each time point, $n=1$ ) reproduced at least three times. B, S. meliloti wild type (Rm1021) containing either the empty plasmid pBBR1-MCS5 (black symbols) or pBBR1-hmp (open symbols) was cultured without (squares) or with (diamonds) $200 \mu \mathrm{M}$ SpNN. Cell density $\left(\mathrm{OD}_{600}\right)$ was measured at the indicated times. The figure shows the results of a typical experiment $(n=1)$ reproduced three times with pBBR-hmp or twice for the empty vector. 


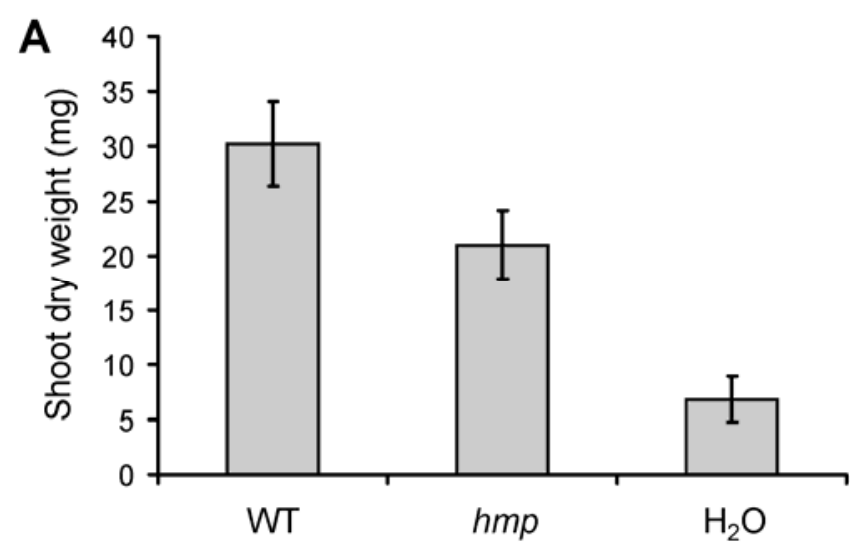

B

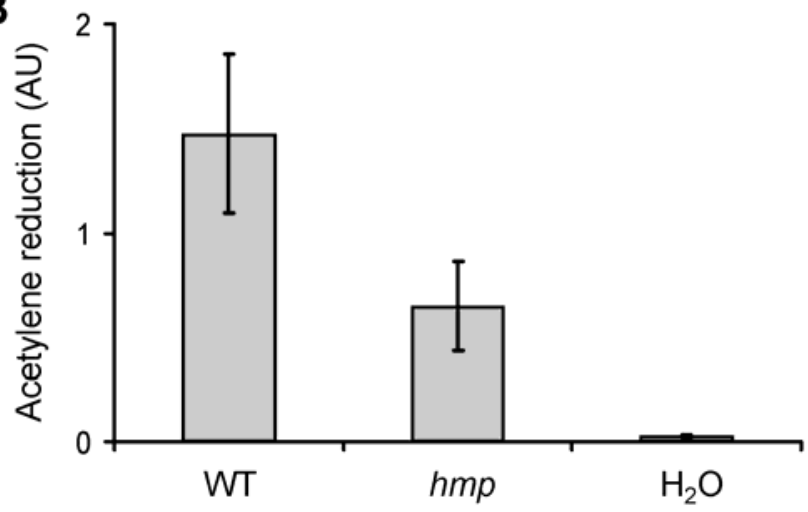

Fig. 4. Hmp is required for efficient nitrogen fixation of Sinorhizobium meliloti in Medicago truncatula nodules. M. truncatula plantlets were inoculated with $S$. meliloti wild type (WT) (Rm2011) or hmp mutant cells (GMI1549). Negative controls were performed where $\mathrm{H}_{2} \mathrm{O}$ was added on the plantlets. At 38 days after inoculation, plants were tested for $\mathbf{A}$, dry weight of the aerial parts of the plants or $\mathbf{B}$, nitrogen fixation efficiency, using an acetylene reduction assay. Values are means \pm standard deviation of data obtained from 10 plants for each strain and five control plants $\left(\mathrm{H}_{2} \mathrm{O}\right)$.

\section{DISCUSSION}

NO produced during infection plays a crucial role in host defense mechanisms. Thus, pathogens evolved mechanisms to detect NO and induce an adaptive response to this molecule in order to survive phagocyte killing. NO may also have a role in symbiotic interactions, because NO is produced in plant root nodules of legumes such as $M$. truncatula (Baudouin et al. 2006) or $M$. sativa (Pii et al. 2007). We can speculate that the role of NO in symbiosis with nitrogen-fixing bacteria would be different from that known in pathogenic interactions; however, the function or functions of $\mathrm{NO}$ are not identified yet. Although the response to nitrosative stress is well documented in many bacteria, data concerning the response of rhizobia to the presence of NO were very limited prior to this study. Our transcriptome analyses show that approximately 100 genes are upregulated by NO in $S$. meliloti grown in culture. If we consider the genes which could have been missed in putative operons, the NO stimulon of $S$. meliloti could comprise up to 130 genes.

The first striking observation of this study was the remarkable overlap between the NO and microaerobic stimulons, because at least $70 \%$ of the genes upregulated by NO had been described before as being induced under microaerobic conditions (Bobik et al. 2006). We rule out the possibility that SpNN itself could have triggered a microaerobic environment because it was shown before that the oxygen tension was identical in a culture containing or not containing this molecule (Ohno et al. 2003). We showed that most of the genes common to the NO and microoxia stimulons are regulated by the two-component system FixLJ (Fig. 5). The NO stimulon includes all the direct targets of FixLJ (i.e., nifA, fixK, and smc03253), confirming that NO acts at the FixLJ level. In S. meliloti, FixJ is a major regulator because it controls two-thirds of the genes induced by microaerobiosis and the majority of rhizobial genes expressed in planta in mature nodules (Bobik et al. 2006). The FixJ cognate sensor histidine kinase FixL possesses a hemebinding domain, and the oxygen-bound form (dissociation

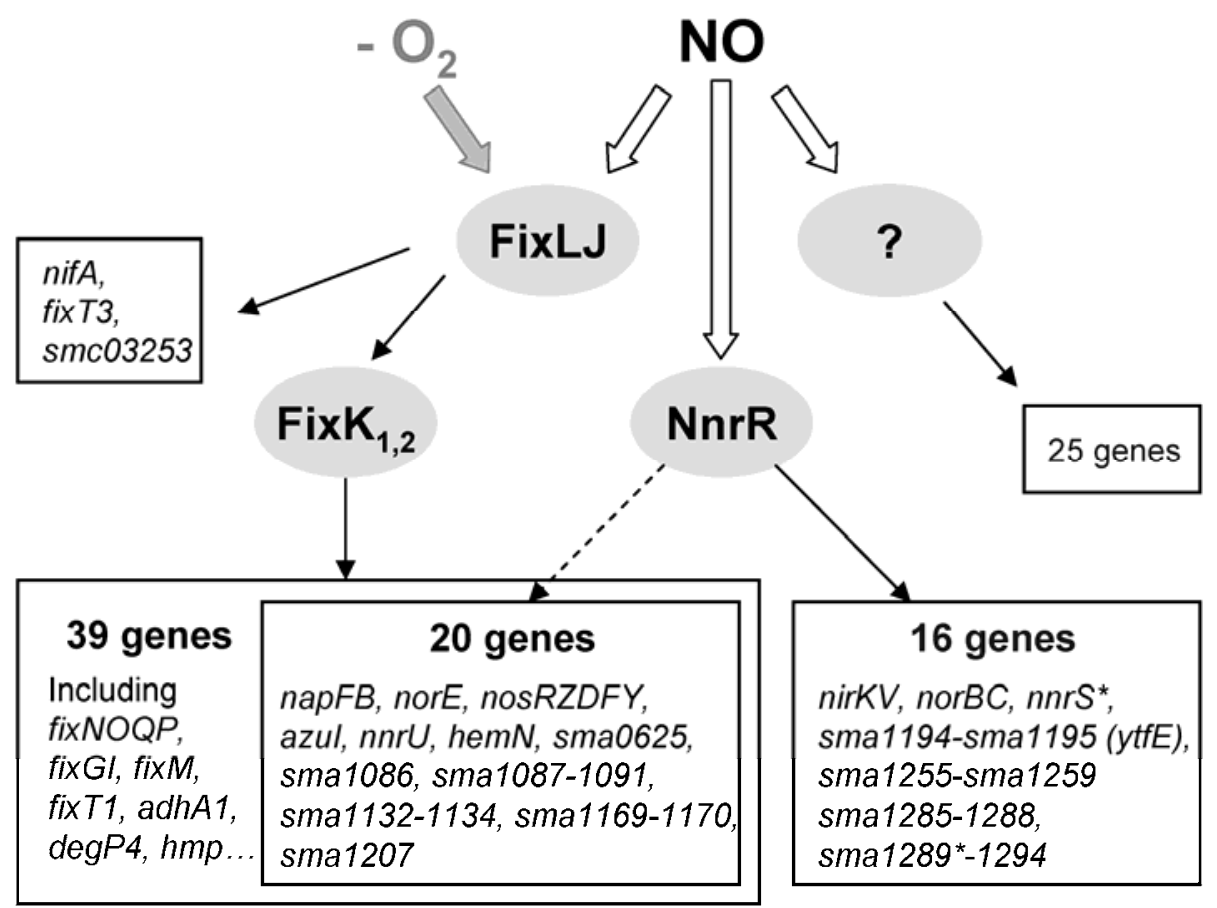

Fig. 5. Regulation of nitric oxide (NO)-induced genes: a schematic model. Number of targets indicated in the boxes is underestimated due to the genes present in the same transcription unit but not found in our study; * indicates genes identified following quantitative reverse-transcription polymerase chain reaction analysis. 
constant 50 to $140 \mu \mathrm{M}$ ) is the off-state whereas the unliganded form is the active kinase (on-state). It has already been known that FixL could bind ligands other than $\mathrm{O}_{2}$ such as $\mathrm{NO}$ and CO. FixL affinity was shown to be higher for $\mathrm{NO}$ than for $\mathrm{O}_{2}$; however, oxygen was the only compound able to abolish its kinase activity ( $>200$-fold inhibition) (Gilles-Gonzalez et al. 2008). Therefore, the on-state of the kinase in the presence of NO could be due to the higher affinity of FixL for NO compared with oxygen. Whether NO signaling via FixLJ has a biological significance in either free-living cells or symbiosis remains to be established. In the soil, S. meliloti is submitted to microoxic conditions and also to nitrogen oxides generated by either denitrifying microorganisms or nitrate supplements. Low oxygen concentrations encountered by $S$. meliloti during symbiosis trigger FixLJ-mediated gene expression (Reyrat et al. 1993). However, NO is present in nodules and may serve as an additional signal to activate the FixLJ regulon. The concentration of NO in nodules has not been determined precisely but is estimated to be in the micromolar range ( $\mathrm{R}$. Brouquisse, personal communication). Heurlier and colleagues (2008) measured the concentration of NO released by $\mathrm{SpNN}$ in the medium. Based on their results, we calculated that NO is in the micromolar range in our experiments (i.e., of the same order of magnitude as that estimated in nodules, where it could therefore be considered as a putative signal for FixL). The availability of plant mutants deficient in NO synthesis could help settle the question of whether NO is a symbiotic signal of the FixLJ signaling pathway; unfortunately, the enzymatic sources of NO in plants are not fully characterized yet (Besson-Bard et al. 2008). In other bacterial species, two-component systems have also been described to respond to NO (Spiro 2007). In Mycobacterium tuberculosis, a significant overlap between the transcriptional responses to NO and hypoxia has been described because, of the 36 genes determined to be NO inducible, 27 were also induced under microaerobic conditions. $M$. tuberculosis DosR is a response regulator that controls the expression of at least 50 genes in response to anoxia. DosR can be phosphorylated by two histidine kinases, DosS and DosT, both of which respond to low oxygen concentration (Roberts et al. 2004). There is good evidence to suggest that the DosRST system is also involved in mediating the response to NO, given that most DosR-regulated genes are induced in activated macrophages in an NO-synthase-dependent manner (Ohno et al. 2003). It has been proposed that NO present at a high concentration during the inflammatory response displaces oxygen from the haem group but is a poor inhibitor of the histidine kinase activity, thus explaining how NO can induce the Dos regulon (Sousa et al. 2007). We reached a similar conclusion with FixLJ in $S$. meliloti.

We confirmed that NnrR, a member of FNR/CRP family, is also involved in the NO response of S. meliloti. NnrR is a dedicated NO sensor, first identified as activating gene transcription in response to NO in a denitrifying strain of $R$. sphaeroides (Tosques et al. 1996). This protein controls the transcription of nor genes, which encode the NO reductase. Surprisingly, the nir $K V$ operon encoding the nitrite reductase responsible for the formation of NO is also a target for NnrR regulation. This coordinated regulation is common in denitrifiers and prevents the toxic accumulation of NO. Rodionov and colleagues (2005) found orthologues of $\mathrm{NnrR}$ in six $\alpha$-proteobacteria, all of which also possess the nir and nor genes involved in denitrification. S. meliloti NnrR was shown previously to regulate, in the presence of NO, an operon (sma1289-sma1294) whose function is yet unknown (de Bruijn et al. 2006). In this study, we confirmed this finding and we identified seven transcription units regulated by NnrR (Table 2). All are located on the symbiotic plasmid pSymA and display a consensus NnrR box in their promoter region $\left(\mathrm{TTTGN}_{8} \mathrm{CAAA}\right)$. Our work agrees with the bioinformatic predictions of Rodionov, who identified eight candidate NnrR targets in $S$. meliloti (Rodionov et al. 2005; Bobik et al. 2006). Our analyses recovered five of these transcription units (sma1195, nirK, nnrS, norC, and sma1289) and found two new ones (sma1259 and sma1288).

For a subset of NO-induced genes, the issue remains whether these genes are controlled by FixK or NnrR in the presence of NO. Both regulators belong to the FNR/CRP family, and their DNA-binding sites display high sequence similarities and sometimes overlap. Hence, we propose that at least some of these genes could be regulated alternately by either FixK or NnrR in the presence of NO, which renders difficult their classification in one regulon or the other.

Another important question is whether or not both regulators FixK and NnrR are on the same signaling pathways. In $B$. japonicum, a model has been described by Mesa and coworkers where $n n r R$ is placed in the FixLJ-FixK ${ }_{2}$ cascade, downstream of the FixK $\mathrm{K}_{2}$ regulator. The expression of $n n r R$ in the wild-type strain is quite low, rendering its expression in the fix $K$ mutant even more difficult to analyze. Also, the FixK box present in the promoter region of $n n r R$ is poorly conserved (Mesa et al. 2003). However, a recent transcriptome analysis confirmed that expression of $n n r R$ is regulated by FixJ and FixK $\mathrm{K}_{2}$ under microaerobic conditions, although this does not seem to be the case in planta (Mesa et al. 2008). This model is unlikely to be applicable to $S$. meliloti because (i) $n n r R$ was not found as a FixK target in a previous transcriptomic study (Bobik et al. 2006), (ii) there is no FixK-box in the promoter region of $n n r R$ in $S$. meliloti, and (iii) we could find genes regulated by $\mathrm{NnrR}$ and not by FixJ/FixK in the presence of NO (i.e., sma1289) (this work and data not shown). On the whole, these data suggest that FixK and NnrR are part of two different signaling pathways, both being responsive to NO.

There are approximately 25 genes for which regulators remain to be found. Various regulators involved in NO response have been described in other bacteria (Spiro 2007); at least two of these regulators (i.e., SoxR and OxyR) are encoded by the genome of $S$. meliloti and could be responsible for NO upregulation of some of these genes. Alternatively, because NO poorly induces expression of most of these, they may not be genuine NO-induced genes. Most of these genes encode hypothetical or poorly characterized proteins.

In terms of physiological response to NO in S. meliloti, hmp, encoding a flavohemoglobin, is a relevant gene. Flavohemoglobins participate in NO detoxification in many organisms and are often pathogenicity determinants. We showed that, in S. meliloti, hmp is clearly involved in NO response because null mutants in this gene displayed a higher sensitivity to NO than the wild type whereas overexpression of Hmp enhanced NO resistance. We further showed that this gene plays a role in symbiosis because $\mathrm{hmp}$ null mutants displayed lower nitrogen fixation efficiency than the wild type. This could be the consequence of NO accumulation in the mutant cells and negative effects of this accumulation on the function of proteins such as the nitrogenase, that has been shown to be sensitive to NO (Trinchant and Rigaud 1982). Hmp converts NO to nitrate or nitrous oxide in aerobic or anaerobic conditions, respectively (Justino et al. 2005). Because microaerobic conditions prevail inside nodules, detoxification of $\mathrm{NO}$ by Hmp could lead to the formation of either nitrate or nitrous oxide, which may both enter the denitrification pathway.

Gene smal195 is similar to Escherichia coli ytfE. The expression of this gene in $E$. coli is increased upon exposure to $\mathrm{NO}$ and it has been shown to be critical for repair of iron clusters damaged by oxidative or nitrosative stress conditions (Justino et al. 2005, 2007; Overton et al. 2008). These repair- 
of-iron-center family proteins are encoded in many pathogen genomes; one has been shown to be essential for Hemophilus influenzae pathogenicity (Harrington et al. 2009). Among the genes induced by NO are those involved in denitrification and in functions related to this process, such as azul (encoding a pseudoazurin), hem $N$ (encoding a coproporphyrinogen III oxidase), $n n r U$ (encoding a putative regulatory protein), and smal252 encoding a member of the NnrS family. NnrS is a putative heme-copper protein and a member of the short-chain dehydrogenase family. This protein has been identified in $R$. sphaeroides and its role, although not studied in details, could be in the denitrification process (Bartnikas et al. 2002). Denitrification is a widespread respiratory pathway in bacteria in which nitrogen oxides are used as electron acceptors in the absence of oxygen, which may explain why most of the denitrification genes are expressed in microaerobic conditions (albeit at a lower level than in the presence of $\mathrm{NO}$ for nitrite reductase-nir and NO reductase-nor). The role of these genes in symbiosis is not known, although denitrification activity has been detected in S. meliloti bacteroids (O'Hara et al. 1983). More recently, bacteroidal nitrate and nitrite reductase activities were also detected in soya bean nodules treated with low concentrations of nitrates (Mesa et al. 2004; Meakin et al. 2007). There is evidence of a role of denitrification genes in the successful interaction of bacteria with their host (Baek et al. 2004; Philippot 2005). Denitrification may serve an energetic function in bacteroids but also as a protection against NO during infection. Indeed, we observed that a norB mutant (encoding NO reductase) is more sensitive to NO than is the wild type in culture (data not shown). Denitrification could protect the nitrogenase against inhibition by nitrate or NO (Lucinski et al. 2002). However, data obtained in B. japonicum indicate that nor gene products are not the only ones responsible for $\mathrm{NO}$ degradation in soya bean nodules and that another detoxification system must exist. It could be a flavohemoglobin because B. japonicum possesses a hmp orthologue in its genome (Meakin et al. 2006).

It was recently described that nitrate reductase, product of the nap genes (but probably not nitrite reductase-nirK), contributes to the formation of NO in soya-bean nodules as measured by the formation of leghemoglobin-NO (Meakin et al. 2007). Hence, bacteria could contribute to the formation of $\mathrm{NO}$ in the nodules. A role for the bacterial NO production has been shown recently in macrophages infected with $B$. anthracis spores, where NO antagonizes the antimicrobial action of the oxidative burst generated by macrophages (Shatalin et al. 2008). A similar role could be conceived in the symbiotic interaction where an oxidative burst occurs in alfalfa early after infection with symbiotic bacteria.

In conclusion, the flavohemoglobin Hmp has emerged as the most significant NO-detoxifying protein in many diverse microorganisms, particularly pathogenic bacteria, and we show here that it could also serve this role in the symbiotic interaction between $S$. meliloti and alfalfa or the model plant legume Medicago truncatula. Other bacterial genes upregulated by NO such as those encoding NO reductase (nor) could be involved in NO detoxifying, perhaps together with plant hemoglobins, which participate in limiting NO toxicity inside nodules. However, the functions of many genes implicated in the NO response are still unknown and their implication in the establishment or maintenance of symbiosis could prove to be more subtle than the sole detoxification function.

\section{MATERIALS AND METHODS}

\section{Bacterial strains and growth conditions.}

The strains and plasmids used in this study are listed in Table 3. S. meliloti strains were grown in aerobic conditions at $28^{\circ} \mathrm{C}$ in Vincent minimal medium (VMM): $5.74 \mathrm{mM} \mathrm{K}_{2} \mathrm{HPO}_{4}$, $7.35 \mathrm{mM} \mathrm{KH}_{2} \mathrm{PO}_{4}, 1 \mathrm{mM} \mathrm{MgSO}$, $18.7 \mathrm{mM} \mathrm{NH}_{4} \mathrm{Cl}, 10 \mathrm{mM}$ $\mathrm{Na}_{2}$ succinate, $456 \mu \mathrm{M} \mathrm{CaCl}_{2}, 35 \mu \mathrm{M} \mathrm{FeCl}_{3}, 4 \mu \mathrm{M}$ biotine, $48.5 \mu \mathrm{M} \mathrm{H}_{3} \mathrm{BO}_{3}, 10 \mu \mathrm{M} \mathrm{MnSO}_{4}, 1 \mu \mathrm{M} \mathrm{ZnSO}_{4}, 0.5 \mu \mathrm{M} \mathrm{CuSO}_{4}$, $0.27 \mu \mathrm{M} \mathrm{CoCl}_{2}$, and $0.5 \mu \mathrm{M} \mathrm{NaMoO}$.

Strain constructions were performed in Luria-Bertani medium supplemented with $2.5 \mathrm{mM} \mathrm{CaCl} 2$ and $2.5 \mathrm{mM} \mathrm{MgSO}_{4}$ (LBMC). Antibiotics were added at the following concentrations: streptomycin (Sm) at 100 to $200 \mu \mathrm{g} \mathrm{ml}^{-1}$, tetracycline (Tc) at $10 \mu \mathrm{g} \mathrm{ml}^{-1}$, gentamicin $(\mathrm{Gm})$ at $40 \mu \mathrm{g} \mathrm{ml}^{-1}$, and neomycin $(\mathrm{Nm})$ at $100 \mu \mathrm{g} \mathrm{ml}^{-1}$.

The NO donor SpNN was purchased from Cayman Chemicals Coger (CAY-82150-M100; Paris). A 100-mM stock solution was prepared, just before use, in Na-phosphate buffer $(0.1$ $\mathrm{M}), \mathrm{pH}$ 6.9, and then diluted in the cell culture medium at the appropriate concentrations.

\section{Strain and plasmid constructions.}

All plasmid constructions were performed in the E. coli DH5 $\alpha$ strain. The DNA sequences of oligonucleotide primers

Table 3. Strains and plasmids used in this study

\begin{tabular}{|c|c|c|}
\hline Strain or plasmid & Description $^{\text {a }}$ & Reference or source \\
\hline \multicolumn{3}{|c|}{ Sinorhizobium meliloti } \\
\hline $\mathrm{Rm} 1021$ & Wild-type strain, SU-47 derived, $\mathrm{Sm}^{\mathrm{r}}$ & Meade et al. 1982 \\
\hline Rm2011 & Wild-type strain, SU-47 derived, $\mathrm{Sm}^{\mathrm{r}}$ & Pobigaylo et al. 2008 \\
\hline EK101 & Rm1021 derivative, fixJ::Tn5 & Ernö Kiss \\
\hline EK104 & Rm1021 derivative, fixL::Tn5 & Ernö Kiss \\
\hline GMI11548 & Rm1021 sma1207 :: pK19 & Anke Becker \\
\hline GMI11549 & Rm2011 hmp :: mTn5-STM-2.12.A01 & Anke Becker \\
\hline CBT515 & Rm1021 nnrR :: pVO155 & Silvia Rosbach \\
\hline CBT731 & Rm1021 sma1289:: pVO155 & This work \\
\hline CBT732 & Rm1021 sma1294 :: pVO155 & This work \\
\hline CBT733 & Rm1021 hmp :: pVO155 & This work \\
\hline \multicolumn{3}{|l|}{ Escherichia coli } \\
\hline DH5 $\alpha$ & 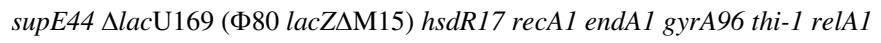 & Sambrook et al. 1989 \\
\hline \multicolumn{3}{|c|}{$\cos ^{2}$} \\
\hline pRK2013 & Helper plasmid for triparental matings & Figurski and Helinski 1979 \\
\hline pGEM-T & Cloning vector, $\mathrm{Amp}^{\mathrm{r}}$ & Promega \\
\hline pBBR1MCS-5 & Cloning vector, $\mathrm{Gm}^{\mathrm{r}}$ derivative of $\mathrm{pBBR} 1$ & Kovach et al. 1995 \\
\hline pVO155 & Integrational plasmid with promoterless uidA gene, $\operatorname{Kan}^{\mathrm{r}}$ & Oke and Long 1999 \\
\hline pGEM-hmp & pGEM-T + hmp & This work \\
\hline pBBR-hmp & pBBR1MCS-5 + hmp & This work \\
\hline
\end{tabular}

${ }^{\mathrm{a}} \mathrm{Sm}^{\mathrm{r}}, \mathrm{Amp}^{\mathrm{r}}, \mathrm{Gm}^{\mathrm{r}}$, and $\mathrm{Kan}^{\mathrm{r}}$ = resistant to streptomycin, ampicillin, gentamicin, and kanamycin, respectively. 
used for PCR amplifications are shown in Supplementary Table S1.

For constructing plasmid pBBR-hmp, a DNA fragment containing the $\mathrm{hmp}$ gene with 100 nucleotides upstream of ATG was generated by PCR (1,319 bp) using primers sma1191exp, genomic DNA of the strain Rm1021 as template, and ligated in pGEM-T plasmid, yielding pGEM-hmp. The cloned S. meliloti DNA region was verified by DNA sequencing. This plasmid was digested with BamHI-XbaI and ligated into BamHI-XbaIdigested pBBR1MCS-5, yielding pBBR-hmp. These plasmids were introduced in $S$. meliloti by triparental mating using pRK2013 as helper.

To construct $S$. meliloti null-mutant strains, DNA fragments of sma1191, sma1289, and smal294 were produced by PCR. PCR products were digested with $\mathrm{Bam} \mathrm{HI}$ and $\mathrm{XbaI}$ and ligated into the BamHI-XbaI digested pVO155 plasmid. The resulting plasmid constructs were checked by sequencing and introduced into $S$. meliloti $\mathrm{Rm} 1021$ by triparental mating. Transconjugants were selected three times on LBMC plates supplemented with $\mathrm{Sm}$ and $\mathrm{Nm}$. A single colony was selected and the correct integration of the plasmid was confirmed by PCR.

\section{Preparation of samples for microarrays and qRT-PCR.}

For microarray and qRT-PCR analyses, strains were grown exponentially at $28^{\circ} \mathrm{C}$ in $25 \mathrm{ml}$ of VMM. At an optical density at $600 \mathrm{~nm}\left(\mathrm{OD}_{600}\right)$ between 0.15 and 0.25 , spermine or SpNN was added at the appropriate concentration. The cultures were incubated at $28^{\circ} \mathrm{C}$ for $30 \mathrm{~min}$; then, cells were collected by filtration and immediately frozen in liquid nitrogen and stored at $-80^{\circ} \mathrm{C}$ until RNA extraction. RNA was prepared from the collected samples as previously described (Bobik et al. 2006), followed by DNaseI treatment (Qiagen clean-up procedure [Qiagen, Hilden, Germany]).

\section{Labeling of hybridization probes, microarray hybridizations, and analyses.}

Cy3- and Cy5-labeled cDNAs were prepared from $20 \mu \mathrm{g}$ of RNA according to Bobik and associates (2006). For each experiment, RNA preparations from at least three independent cultures were used. Sm14kOLI microarrays were purchased from A. Becker (University of Bielefeld, Germany). They consisted of glass slides carrying mainly 70-mer oligonucleotides representative of the 6,208 predicted open reading frames of $S$. meliloti spotted in duplicate, as well as 50- to 70-mer oligonucleotides representative of intergenic regions, and a number of control spots. Hybridizations were performed as described previously (Bobik et al. 2006). Data were acquired on a GenePix 4000 scanner (Axon Instruments, Sunnyvale, CA, U.S.A.) and quantification of mean signal intensities for each spot was performed using GenePix Pro 3.0 (Axon Instruments). Data analyses were carried out using Genesight (version 3.5; Biodiscovery Inc., El Segundo, CA, U.S.A.) with normalization by median of the signal and statistical $t$ test. The whole set of data is available at ArrayExpress (accession E-MEXP-2515).

\section{qRT-PCR analyses.}

RT was performed using Superscript II reverse transcriptase (Invitrogen, Carlsbad, CA, U.S.A.) and random hexamers as primers. RNA samples isolated from at least three independent cultures were tested for each condition. Real-time PCR tests were run on a LightCycler system (Roche, Mannheim, Germany) using the FastStart DNA Master SYBRGreen I kit (Roche) according to the manufacturer's instructions. 16S rRNA was used as a reference for normalization. In these experiments, we observed variability between biological repeats. It may be due to the degradation kinetic of SpNN (particularly dependent upon $\mathrm{pH}$ and temperature of the medium), which may vary slightly from one culture to another and, hence, impact the level of NO-induced gene expression. Also, $\mathrm{SpNN}$ is not stable in solution and, hence, must be prepared just before each experiment by weighing very small amounts of the molecule, which may be another source of variability.

\section{Plant assays.}

Seeds of $M$. sativa cv. Europe or M. truncatula cv. Jemalong A17 were surface sterilized, germinated on agar plates, and allowed to grow on nitrogen-free Fahreus medium in test tubes during three (M. sativa) or two (M. truncatula) days (Barker et al. 2006). Plants were inoculated (S. meliloti strains at 100 $\mu \mathrm{l} /$ plant resuspended in sterile water at $\left.\mathrm{OD}_{600}=0.001\right)$. Series of 10 plants were inoculated with either the wild type or the different mutants, and series of five plants were inoculated with $100 \mu \mathrm{l}$ of water as controls. Plants were grown in a culture room $\left(22^{\circ} \mathrm{C}\right)$ with day and night cycles of 16 and $8 \mathrm{~h}$, respectively. Dry weights of the plant shoots were measured 38 days after inoculation.

Nitrogenase activity was determined by the acetylene reduction assay (Hardy et al. 1968). Nitrogen fixation was assayed using plants grown in test tubes fitted with rubber stoppers. Air $(6 \mathrm{ml})$ was removed from the tubes and the same amount of acetylene was added. Gas samples $(200 \mu \mathrm{l})$ were taken after $2.5 \mathrm{~h}$ and analyzed for ethylene and acetylene in a gas chromatograph equipped with a hydrogen flame ionization detector (Intersmat IGC 120FL). For each plant, the amount of ethylene produced is assessed by measuring the height of the ethylene peak on the chromatogram.

\section{Gus activity assay.}

$S$. meliloti cells were grown to exponential phase at $28^{\circ} \mathrm{C}$ in VMM. At $\mathrm{OD}_{600}=0.2, \mathrm{SpNN}$ was added and the cultures were incubated at $28^{\circ} \mathrm{C}$ for the indicated times. Aliquots of 300 or $1,000 \mu \mathrm{l}$ were centrifuged and resuspended in $300 \mu \mathrm{l}$ of sterile water. Gus activity was assayed on the samples as referenced by Blanvillain and associates (2007).

\section{ACKNOWLEDGMENTS}

We thank F. de Bruijn for critical reading of the manuscript; E.-P. Journet for providing seeds of $M$. truncatula and for helpful discussions; L. Sauviac for critical reading of the manuscript, many helpful discussions, and technical support; E. Kiss and S. Rossbach for constructing some mutants; A. Becker for making it possible to purchase $S$. meliloti microarrays and for providing us some $S$. meliloti mutants; S. Carrère for bioinformatic support; and all of our colleagues from the "PIANO group," especially A. Boscari, R. Brouquisse, and A. Puppo, for all the stimulating discussions we had together. E. Meilhoc was supported by the National Institute for Applied Sciences (INSA-Toulouse); Y. Cam was a recipient of a "Contrat Jeune Scientifique INRA." This study was supported in part by a grant from the Agence Nationale de la Recherche (BLAN07-2_184783).

\section{LITERATURE CITED}

Angelo, M., Hausladen, A., Singel, D. J., and Stamler, J. S. 2008. Interactions of NO with hemoglobin: from microbes to man. Methods Enzymol. 436:131-168.

Baek, S. H., Rajashekara, G., Splitter, G. A., and Shapleigh, J. P. 2004. Denitrification genes regulate Brucella virulence in mice. J. Bacteriol. 186:6025-6031

Bang, I. S., Liu, L., Vazquez-Torres, A., Crouch, M. L., Stamler, J. S., and Fang, F. C. 2006. Maintenance of nitric oxide and redox homeostasis by the salmonella flavohemoglobin hmp. J. Biol. Chem. 281:28039-28047.

Barker, D. G., Pfaff, T., Moreau, D., Groves, E., Vazquez-Torres, A., Lepetit, M., Whitehand, S., Maillet, F., Nair, R. M., and Journet, E.-P. 2006. Growing M. truncatula: choice of substrates and growth conditions. In: The Medicago truncatula Handbook. The Samuel Roberts Noble Foundation, Ardmore, OK, U.S.A. Published online.

Bartnikas, T. B., Wang, Y., Bobo, T., Veselov, A., Scholes, C. P., and Shapleigh, J. P. 2002. Characterization of a member of the NnrR regu- 
lon in Rhodobacter sphaeroides 2.4 .3 encoding a haem-copper protein Microbiology 148:825-833.

Baudouin, E., Pieuchot, L., Engler, G., Pauly, N., and Puppo, A. 2006. Nitric oxide is formed in Medicago truncatula-Sinorhizobium meliloti functional nodules. Mol. Plant-Microbe Interact. 19:970-975.

Bedmar, E. J., Robles, E. F., and Delgado, M. J. 2005. The complete denitrification pathway of the symbiotic, nitrogen-fixing bacterium Bradyrhizobium japonicum. Biochem. Soc. Trans. 33:141-144.

Besson-Bard, A., Pugin, A., and Wendehenne, D. 2008. New insights into nitric oxide signaling in plants. Annu. Rev. Plant Biol. 59:21-39.

Blanvillain, S., Meyer, D., Boulanger, A., Lautier, M., Guynet, C., Denance, N., Vasse, J., Lauber, E., and Arlat, M. 2007. Plant carbohydrate scavenging through tonb-dependent receptors: a feature shared by phytopathogenic and aquatic bacteria. PLoS ONE 2:e224.

Bobik, C., Meilhoc, E., and Batut, J. 2006. FixJ: a major regulator of the oxygen limitation response and late symbiotic functions of Sinorhizobium meliloti. J. Bacteriol. 188:4890-4902.

Boccara, M., Mills, C. E., Zeier, J., Anzi, C., Lamb, C., Poole, R. K., and Delledonne, M. 2005. Flavohaemoglobin HmpX from Erwinia chrysanthemi confers nitrosative stress tolerance and affects the plant hypersensitive reaction by intercepting nitric oxide produced by the host. Plant J. 43:226-237.

Cross, R., Aish, J., Paston, S. J., Poole, R. K., and Moir, J. W. 2000. Cytochrome $\mathrm{c}^{\prime}$ from Rhodobacter capsulatus confers increased resistance to nitric oxide. J. Bacteriol. 182:1442-1447.

Davidson, S. K., Koropatnick, T. A., Kossmehl, R., Sycuro, L., and McFall-Ngai, M. J. 2004. NO means 'yes' in the squid-Vibrio symbiosis: nitric oxide (NO) during the initial stages of a beneficial association. Cell Microbiol. 6:1139-1151.

de Bruijn, F. J., Rossbach, S., Bruand, C., and Parrish, J. R. 2006. A highly conserved Sinorhizobium meliloti operon is induced microaerobically via the FixLJ system and by nitric oxide (NO) via NnrR. Environ. Microbiol. 8:1371-1381.

Dominguez-Ferreras, A., Perez-Arnedo, R., Becker, A., Olivares, J., Soto, M. J., and Sanjuan, J. 2006. Transcriptome profiling reveals the importance of plasmid pSymB for osmoadaptation of Sinorhizobium meliloti. J. Bacteriol. 188:7617-7625.

Elvers, K. T., Wu, G., Gilberthorpe, N. J., Poole, R. K., and Park, S. F. 2004. Role of an inducible single-domain hemoglobin in mediating resistance to nitric oxide and nitrosative stress in Campylobacter jejuni and Campylobacter coli. J. Bacteriol. 186:5332-5341.

Favey, S., Labesse, G., Vouille, V., and Boccara, M. 1995. Flavohaemoglobin HmpX: a new pathogenicity determinant in Erwinia chrysanthemi strain 3937. Microbiology 141:863-871.

Figurski, D. H., and Helinski, D. R. 1979. Replication of an origin-containing derivative of plasmid RK2 dependent on a plasmid function provided in trans. Proc. Natl. Acad. Sci. U.S.A. 76:1648-1652.

Foussard, M., Garnerone, A. M., Ni, F., Soupene, E., Boistard, P., and Batut, J. 1997. Negative autoregulation of the Rhizobium meliloti fixK gene is indirect and requires a newly identified regulator, FixT. Mol. Microbiol. 25:27-37.

Gardner, P. R. 2005. Nitric oxide dioxygenase function and mechanism of flavohemoglobin, hemoglobin, myoglobin and their associated reductases. J. Inorg. Biochem. 99:247-266.

Gardner, P. R., Gardner, A. M., Martin, L. A., and Salzman, A. L. 1998 Nitric oxide dioxygenase: an enzymic function for flavohemoglobin. Proc. Natl. Acad. Sci. U.S.A. 95:10378-10383.

Gilles-Gonzalez, M. A., Gonzalez, G., Sousa, E. H., and Tuckerman, J. 2008. Oxygen-sensing histidine-protein kinases: assays of ligand binding and turnover of response-regulator substrates. Methods Enzymol. 437:173-189.

Hardy, R. W., Holsten, R. D., Jackson, E. K., and Burns, R. C. 1968. The acetylene-ethylene assay for $\mathrm{N}(2)$ fixation: laboratory and field evaluation. Plant Physiol. 43:1185-1207.

Harrington, J. C., Wong, S. M., Rosadini, C. V., Garifulin, O., Boyartchuk, V., and Akerley, B. J. 2009. Resistance of Haemophilus influenzae to reactive nitrogen donors and gamma interferon-stimulated macrophages requires the formate-dependent nitrite reductase regulator-activated ytfE gene. Infect. Immun. 77:1945-1958.

Heurlier, K., Thomson, M. J., Aziz, N., and Moir, J. W. 2008. The nitric oxide (NO)-sensing repressor NsrR of Neisseria meningitidis has a compact regulon of genes involved in NO synthesis and detoxification. J. Bacteriol. 190:2488-2495.

Justino, M. C., Vicente, J. B., Teixeira, M., and Saraiva, L. M. 2005. New genes implicated in the protection of anaerobically grown Escherichia coli against nitric oxide. J. Biol. Chem. 280:2636-2643.

Justino, M. C., Almeida, C. C., Teixeira, M., and Saraiva, L. M. 2007. Escherichia coli di-iron YtfE protein is necessary for the repair of stress-damaged iron-sulfur clusters. J. Biol. Chem. 282:10352-10359.

Kovach, M. E., Elzer, P. H., Hill, D. S., Robertson, G. T., Farris, M. A.,
Roop, R. M., 2nd, and Peterson, K. M. 1995. Four new derivatives of the broad-host-range cloning vector pBBR1MCS, carrying different antibiotic-resistance cassettes. Gene 166:175-176.

Laratta, W. P., and Shapleigh, J. P. 2003. Site-directed mutagenesis of NnrR: a transcriptional regulator of nitrite and nitric oxide reductase in Rhodobacter sphaeroides. FEMS (Fed. Eur. Microbiol. Soc.) Microbiol. Lett. 229:173-178.

Lira-Ruan, V., Sarath, G., Klucas, R. V., and Arredondo-Peter, R. 2003. In silico analysis of a flavohemoglobin from Sinorhizobium meliloti strain 1021. Microbiol. Res. 158:215-227.

Loisel-Meyer, S., Jimenez de Bagues, M. P., Basseres, E., Dornand, J., Kohler, S., Liautard, J. P., and Jubier-Maurin, V. 2006. Requirement of norD for Brucella suis virulence in a murine model of in vitro and in vivo infection. Infect. Immun. 74:1973-1976.

Lucinski, R., Polcyn, W., and Ratajczak, L. 2002. Nitrate reduction and nitrogen fixation in symbiotic association Rhizobium-legumes. Acta Biochim. Pol. 49:537-546.

Mathieu, C., Moreau, S., Frendo, P., Puppo, A., and Davies, M. J. 1998. Direct detection of radicals in intact soybean nodules: presence of nitric oxide-leghemoglobin complexes. Free Radic. Biol. Med. 24:1242-1249.

Meade, H. M., Long, S. R., Ruvkun, G. B., Brown, S. E., and Ausubel, F. M. 1982. Physical and genetic characterization of symbiotic and auxotrophic mutants of Rhizobium meliloti induced by transposon Tn5 mutagenesis. J. Bacteriol. 149:114-122.

Meakin, G. E., Jepson, B. J., Richardson, D. J., Bedmar, E. J., and Delgado, M. J. 2006. The role of Bradyrhizobium japonicum nitric oxide reductase in nitric oxide detoxification in soya bean root nodules. Biochem. Soc. Trans. 34:195-196.

Meakin, G. E., Bueno, E., Jepson, B., Bedmar, E. J., Richardson, D. J., and Delgado, M. J. 2007. The contribution of bacteroidal nitrate and nitrite reduction to the formation of nitrosylleghaemoglobin complexes in soybean root nodules. Microbiology 153:411-419.

Mesa, S., Bedmar, E. J., Chanfon, A., Hennecke, H., and Fischer, H. M. 2003. Bradyrhizobium japonicum NnrR, a denitrification regulator, expands the FixLJ-FixK2 regulatory cascade. J. Bacteriol. 185:39783982

Mesa, S., de Dios Alche, J., Bedmar, E., and Delgado, M. J. 2004. Expression of nir, nor and nos denitrification genes from Bradyrhizobium japonicum in soybean root nodules. Physiol. Plant. 120:205-211.

Mesa, S., Hauser, F., Friberg, M., Malaguti, E., Fischer, H. M., and Hennecke, H. 2008. Comprehensive assessment of the regulons controlled by the FixLJ-FixK2-FixK1 cascade in Bradyrhizobium japonicum. J. Bacteriol. 190:6568-6579.

Moore, C. M., Nakano, M. M., Wang, T., Ye, R. W., and Helmann, J. D. 2004. Response of Bacillus subtilis to nitric oxide and the nitrosating agent sodium nitroprusside. J. Bacteriol. 186:4655-4664.

Mur, L. A., Carver, T. L., and Prats, E. 2006. NO way to live; the various roles of nitric oxide in plant-pathogen interactions. J. Exp. Bot. 57:489 505.

Nagata, M., Murakami, E., Shimoda, Y., Shimoda-Sasakura, F., Kucho, K., Suzuki, A., Abe, M., Higashi, S., and Uchiumi, T. 2008. Expression of a class 1 hemoglobin gene and production of nitric oxide in response to symbiotic and pathogenic bacteria in Lotus japonicus. Mol. PlantMicrobe Interact. 21:1175-1183.

O'Hara, G. W., Daniel, R. M., and Steele, K. W. 1983. Effect of oxygen on the synthesis, activity and breakdown of the Rhizobium denitrification system. J. Gen. Microbiol. 129:2405-2412.

Ohno, H., Zhu, G., Mohan, V. P., Chu, D., Kohno, S., Jacobs, W. R., Jr., and Chan, J. 2003. The effects of reactive nitrogen intermediates on gene expression in Mycobacterium tuberculosis. Cell Microbiol. 5:637648.

Oke, V., and Long, S. R. 1999. Bacterial genes induced within the nodule during the Rhizobium-legume symbiosis. Mol. Microbiol. 32:837-849.

Overton, T. W., Justino, M. C., Li, Y., Baptista, J. M., Melo, A. M., Cole, J. A., and Saraiva, L. M. 2008. Widespread distribution in pathogenic bacteria of di-iron proteins that repair oxidative and nitrosative damage to iron-sulfur centers. J. Bacteriol. 190:2004-2013.

Philippot, L. 2005. Denitrification in pathogenic bacteria: for better or worst? Trends Microbiol. 13:191-192.

Pii, Y., Crimi, M., Cremonese, G., Spena, A., and Pandolfini, T. 2007. Auxin and nitric oxide control indeterminate nodule formation. BMC Plant Biol. 7:21.

Pobigaylo, N., Szymczak, S., Nattkemper, T. W., and Becker, A. 2008. Identification of genes relevant to symbiosis and competitiveness in Sinorhizobium meliloti using signature-tagged mutants. Mol. Plant-Microbe Interact. 21:219-231.

Reyrat, J. M., David, M., Blonski, C., Boistard, P., and Batut, J. 1993. Oxygen-regulated in vitro transcription of Rhizobium meliloti nifA and fixK genes. J. Bacteriol. 175:6867-6872.

Richardson, A. R., Dunman, P. M., and Fang, F. C. 2006. The nitrosative 
stress response of Staphylococcus aureus is required for resistance to innate immunity. Mol. Microbiol. 61:927-939.

Roberts, D. M., Liao, R. P., Wisedchaisri, G., Hol, W. G., and Sherman, D. R. 2004. Two sensor kinases contribute to the hypoxic response of $M y$ cobacterium tuberculosis. J. Biol. Chem. 279:23082-23087.

Rodionov, D. A., Dubchak, I. L., Arkin, A. P., Alm, E. J., and Gelfand, M. S. 2005. Dissimilatory metabolism of nitrogen oxides in bacteria: comparative reconstruction of transcriptional networks. PLoS Comput. Biol. $1: e 55$.

Sambrook, J., Fritsch, E. F., and Maniatis, T. 1989. Molecular Cloning: A Laboratory Manual, 2nd ed. Cold Spring Harbor Laboratory Press, Cold Spring Harbor, NY, U.S.A.

Sauviac, L., Philippe, H., Phok, K., and Bruand, C. 2007. An extracytoplasmic function sigma factor acts as a general stress response regulator in Sinorhizobium meliloti. J. Bacteriol. 189:4204-4216.

Shatalin, K., Gusarov, I., Avetissova, E., Shatalina, Y., McQuade, L. E., Lippard, S. J., and Nudler, E. 2008. Bacillus anthracis-derived nitric oxide is essential for pathogen virulence and survival in macrophages. Proc. Natl. Acad. Sci. U.S.A. 105:1009-1013.

Shimoda, Y., Nagata, M., Suzuki, A., Abe, M., Sato, S., Kato, T., Tabata, S., Higashi, S., and Uchiumi, T. 2005. Symbiotic rhizobium and nitric oxide induce gene expression of non-symbiotic hemoglobin in Lotus japonicus. Plant Cell Physiol. 46:99-107.

Shimoda, Y., Shimoda-Sasakura, F., Kucho, K., Kanamori, N., Nagata, M., Suzuki, A., Abe, M., Higashi, S., and Uchiumi, T. 2009. Overexpression of class 1 plant hemoglobin genes enhances symbiotic nitrogen fixation activity between Mesorhizobium loti and Lotus japonicus. Plant J. 57:254-263.

Sousa, E. H., Tuckerman, J. R., Gonzalez, G., and Gilles-Gonzalez, M. A. 2007. DosT and DevS are oxygen-switched kinases in Mycobacterium tuberculosis. Protein Sci. 16:1708-1719.

Spiro, S. 2007. Regulators of bacterial responses to nitric oxide. FEMS (Fed. Eur. Microbiol. Soc.) Microbiol. Rev. 31:193-211.

Spiro, S. 2008. Metalloregulatory proteins and nitric oxide signalling in bacteria. Biochem. Soc. Trans. 36:1160-1164.

Stevanin, T. M., Moir, J. W., and Read, R. C. 2005. Nitric oxide detoxification systems enhance survival of Neisseria meningitidis in human macrophages and in nasopharyngeal mucosa. Infect. Immun. 73:33223329.

Stevanin, T. M., Read, R. C., and Poole, R. K. 2007. The hmp gene encoding the NO-inducible flavohaemoglobin in Escherichia coli confers a protective advantage in resisting killing within macrophages, but not in vitro: links with swarming motility. Gene 398:62-68.

Tosques, I. E., Shi, J., and Shapleigh, J. P. 1996. Cloning and characterization of $n n r R$, whose product is required for the expression of proteins involved in nitric oxide metabolism in Rhodobacter sphaeroides 2.4.3. J. Bacteriol. 178:4958-4964.

Trinchant, J. C., and Rigaud, J. 1982. Nitrite and nitric oxide as inhibitors of nitrogenase from soybean bacteroids. Appl. Environ. Microbiol. 44:1385-1388 